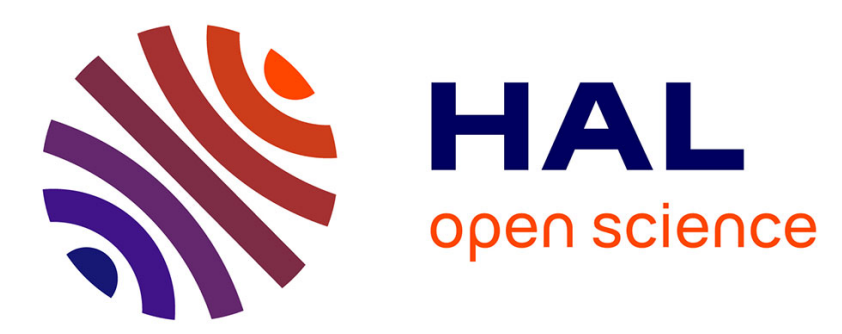

\title{
Dewetting of patterned solid films: Towards a predictive modelling approach
}

\author{
M. Trautmann, F. Cheynis, F. Leroy, S. Curiotto, O. Pierre-Louis, Pierre \\ Müller
}

\section{- To cite this version:}

M. Trautmann, F. Cheynis, F. Leroy, S. Curiotto, O. Pierre-Louis, et al.. Dewetting of patterned solid films: Towards a predictive modelling approach. Applied Physics Letters, 2017, 110 (26), pp.263105. 10.1063/1.4990005 . hal-01617089

\section{HAL Id: hal-01617089 \\ https://hal.science/hal-01617089}

Submitted on 4 May 2018

HAL is a multi-disciplinary open access archive for the deposit and dissemination of scientific research documents, whether they are published or not. The documents may come from teaching and research institutions in France or abroad, or from public or private research centers.
L'archive ouverte pluridisciplinaire HAL, est destinée au dépôt et à la diffusion de documents scientifiques de niveau recherche, publiés ou non, émanant des établissements d'enseignement et de recherche français ou étrangers, des laboratoires publics ou privés. 


\section{Dewetting of patterned solid films: Towards a predictive modelling approach}

M. Trautmann, F. Cheynis, F. Leroy, S. Curiotto, O. Pierre-Louis, and P. Müller

Citation: Appl. Phys. Lett. 110, 263105 (2017); doi: 10.1063/1.4990005

View online: http://dx.doi.org/10.1063/1.4990005

View Table of Contents: http://aip.scitation.org/toc/apl/110/26

Published by the American Institute of Physics

A $1 \mathrm{P} \mid$ Applied Physics AlP Letters

Save your money for your research.

It's now FREE to publish with us no page, color or publication charges apply. 


\title{
Dewetting of patterned solid films: Towards a predictive modelling approach
}

\author{
M. Trautmann, ${ }^{1}$ F. Cheynis, ${ }^{1}$ F. Leroy, ${ }^{1}$ S. Curiotto, ${ }^{1}$ O. Pierre-Louis, ${ }^{2}$ and P. Müller ${ }^{1, a)}$ \\ ${ }^{1}$ Aix Marseille Univ, CNRS, CINaM, 13288 Marseille Cedex 9, France \\ ${ }^{2}$ Institut Lumière Matière, UMR5306 Université Lyon 1-CNRS, Université de Lyon, 69622 Villeurbanne, \\ France
}

(Received 11 May 2017; accepted 13 June 2017; published online 26 June 2017)

\begin{abstract}
Owing to its ability to produce an assembly of nanoislands with controllable size and locations, the solid state dewetting of patterned films has recently received great attention. A simple Kinetic Monte Carlo model based on two reduced energetic parameters allows one to reproduce experimental observations of the dewetting morphological evolution of patterned films of $\operatorname{Si}(001)$ on $\mathrm{SiO}_{2}$ (or $\mathrm{SOI}$ for Silicon-on-Insulator) with various pattern designs. Thus, it is now possible to use KMC to drive further experiments and to optimize the pattern shapes to reach a desired dewetted structure. Comparisons between KMC simulations and dewetting experiments, at least for wire-shaped patterns, show that the prevailing dewetting mechanism depends on the wire width. Published by AIP Publishing. [http://dx.doi.org/10.1063/1.4990005]
\end{abstract}

In recent years, many efforts have been made for using solid state dewetting to form well-ordered 3D crystallites. ${ }^{1-4}$ However, the spontaneous agglomeration of a thin film into $3 \mathrm{D}$ crystallites generally occurs at defects and thus is difficult to control. ${ }^{4}$ It has been shown recently that the use of patterned films may provide a route to obtain specific arrangements of 3D islands. ${ }^{5-10}$ More precisely, by means of well-chosen parameters, the patterns can be designed to create nanostructured surface areas with high precision. Since these first proof-of-concepts, many authors have used lithography to form various patterns to obtain the dewetted structures of choice of interest. ${ }^{11-14}$ However, this experimental approach is time consuming and thus does not allow one to explore numerous configurations. In this letter, we show that a simple Kinetic Monte Carlo model based on only two reduced energetic parameters allows one to reproduce the dewetting behavior of many pattern geometries. Instead of long-lasting experiments using the trial-and-error method, it is possible to save a large amount of time and select beforehand the best pattern shapes by KMC simulations to adapt the dewetted geometries to the application requirements and thus optimize the final results. In the first part, we will describe the KMC model and then we will compare simulated results to SOI (silicon-on-insulator) experimental dewetting patterns for various shapes as rings, crosses, and wires widely used in the literature. ${ }^{5-10}$ Moreover, comparisons between KMC simulations and dewetting experiments enable us to show that the prevailing dewetting mechanism depends on the pattern width.

In the KMC model, ${ }^{15,16}$ a user-defined pattern of material $\mathrm{A}$ is placed on a flat and frozen substrate (B). Units of A occupy a simple cubic lattice, bound by energy $-n J$, where $n$ is the number of in-plane nearest neighbors. Units of $\mathrm{A}$ in direct contact with the substrate have an additional energy $E_{s}$, which is the dewetting driving force. The dewetting is limited by the size of the patterned area and starts from the edges of the pattern. Then, the system evolves by moving units of $\mathrm{A}$ to nearest-neighbor sites at rates

\footnotetext{
${ }^{a)}$ Electronic mail: muller@cinam.univ-mrs.fr
}

$\nu=\nu_{o} \exp \left(-\left(n J-\delta_{0 i} E_{s}\right) / k_{B} T\right)$, where $\delta_{0 i}$ is the Kronecker symbol and $\mathrm{i}=0,1,2,3, \ldots$ is the layer in which the A unit sits. The KMC model is based on only two reduced parameters: $E_{s} / J$ and $k_{B} T / J$. We have already shown that, for $\mathrm{Si}(001)$ on $\mathrm{SiO}_{2}$, this KMC model reproduces the morphological evolution and all the salient features during spontaneous dewetting of a continuous film provided that $E_{S} /$ $J=3 \pm 1$ and $k_{B} T / J=0.5 \pm 0.1 .^{16}$ In the KMC simulations, the $\langle 100\rangle$ orientation corresponds to the direction of nearest neighbors. As a consequence, $\langle 100\rangle$ orientations in KMC actually correspond to $\langle 110\rangle$ orientations in SOI experiments. ${ }^{16}$ The crystallographic orientations used in this paper correspond to the experiments.

We now use the KMC model to simulate dewetting starting from various patterns such as rings, crosses, and wires used in recent experiments ${ }^{4,11-14}$ and to compare the simulated dewetted states to experimental dewetted states. For obvious simulation-time limitation reasons, KMC simulations cannot be performed with objects as large as those used in experiments. KMC simulations have thus been performed on smaller objects (2 ML-thick). As the film is very thin in the simulations, we need to forbid the spontaneous formation of holes in the film away from the film edge. In these conditions, KMC results can be calibrated by comparing pixels in $\mathrm{KMC}$ images and lengths in experiments to have a similar island density. To facilitate the comparison between experimental and simulated patterns, the color code used for the KMC simulations shows the $\mathrm{Si}(001)$ substrate (non-patterned areas) in black, $\mathrm{SiO}_{2}$ as buried oxide (BOX, initially patterned area) in grey, and the dewetted Si islands colored depending on their height. For comparison, SEM images and corresponding $\mathrm{KMC}$ snapshots are reported next to each other.

For the experiments, SOI samples with $20 \mathrm{~nm} \mathrm{Si(001)}$ on top of $150 \mathrm{~nm}$ thick amorphous $\mathrm{SiO}_{2}$ as $\mathrm{BOX}$ were used. The samples were cleaned and prepared as described elsewhere. ${ }^{17}$ The experimental results have been obtained in three steps: (i) fabrication of patterns by electron-beam lithography, (ii) dewetting induced by annealing at temperatures between $860^{\circ} \mathrm{C}$ and $920^{\circ} \mathrm{C}$ under ultrahigh vacuum 
conditions to avoid any influence of the deoxidation mechanism, ${ }^{18}$ and (iii) SEM observations for various annealing conditions in order to illustrate intermediate stages before complete dewetting. Samples were annealed for $3 \mathrm{~min}$ at $860^{\circ} \mathrm{C}$ (experimental condition A), $10 \mathrm{~min}$ at $860^{\circ} \mathrm{C}$ (experimental condition B), and $3 \mathrm{~min}$ at $880^{\circ} \mathrm{C}$ followed by $4 \mathrm{~min}$ at $920^{\circ} \mathrm{C}$ for a complete dewetting (experimental condition $\mathrm{C}$ ).

Figures 1(a) and 1(b) show SEM images and KMC simulations for a ring pattern. By scaling the dewetted island densities obtained by $\mathrm{KMC}$ and experiments, it is possible to calibrate the KMC simulations. For the ring pattern, 30 pixels in the KMC simulation correspond to $1 \mu \mathrm{m}$ in the experiment. Applying this calibration to the numerous simulations that we have performed, we obtain a very good match with all the experimental data. We can clearly see in Figs. 1(a) and 1(b) that both in experiments and simulations, the fronts retract from the inner and from the outer edge of the pattern forming thin wires subsequently breaking up into isolated dots. The crystallographic orientations correspond well with the observations for the dewetting of unpatterned SOI samples. ${ }^{16,19,20}$ For a narrow ring [Figs. 1(c) and 1(d)], the good agreement of the experiment and simulation is confirmed. The dewetting forms a single line of islands on the ring pattern. Finally, after a complete dewetting of the patterns, we obtain randomly distributed isolated $\mathrm{Si}$ islands with comparable densities in the experiment and simulations. We have used Atomic Force Microscopy to measure the distribution

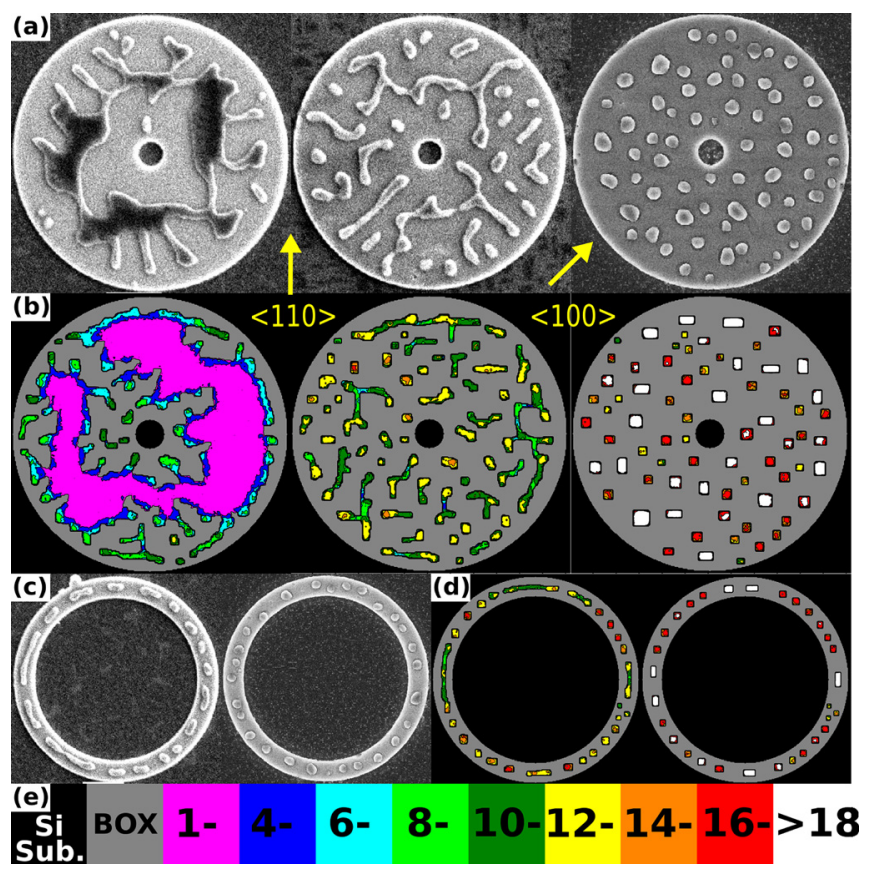

FIG. 1. (a) SEM images of a ring motif with $5 \mu \mathrm{m}$ radius and $4.5 \mu \mathrm{m}$ ring width after different stages of dewetting. Experimental conditions: left, A; center, B; and right, $\mathrm{C}$ (see text). (b) Corresponding KMC-simulations with $\mathrm{h}=2, \mathrm{~T}=0.5, \mathrm{E}_{S}=2, \mathrm{~J}=1$, and $300 \times 300 \mathrm{pix}^{2}$, with the 150 pix radius and 135 pix ring width. The images are taken after 1000 (left), 2000 (center), and 20000 (right) iterations. (c) SEM images of a ring motif with $5 \mu \mathrm{m}$ radius and $1 \mu \mathrm{m}$ ring width after different stages of dewetting (experimental conditions $\mathrm{A}$ and $\mathrm{C}$ ). (d) Corresponding KMC-simulations with $\mathrm{h}=2$, $\mathrm{T}=0.5, \mathrm{E}_{S}=2$, and $300 \times 300 \mathrm{pix}^{2}$, with 150 pix radius and 30 pix ring width. The images are taken after 1000 and 20000 iterations. (e) Color Code for the height in pixels.in SEM the number of escaped electrons varies as a function of the local slope. Therefore in (a) the contrast varies from dark (flat and thin zones) to bright (thicker zones induced by the dewetting). of island heights $(\mathrm{H})$ in the dewetted state. We find $H=100$ $\pm 20 \mathrm{~nm}$, which means a thickening factor $\rho=H / h=5 \pm 1$ as in Ref. 4. In KMC simulations, this ratio is greater $(\rho \approx 10 \pm 2)$ but has the same order of magnitude as in experiments and thus confirms that many features of dewetting in SOI systems can be reproduced with our minimal KMC model.

Since in simulations only first-neighbor interactions have been considered, the island shapes in KMC simulations are less rounded than in experimental SEM images. Moreover, the presence of tiny amounts of carbon contaminants ${ }^{17}$ and temperature effects may also favor more rounded experimental island shapes. Modeling the details of the anisotropy would require improved simulation methods with tunable anisotropy.

Following the same lines as for the ring patterns, we have examined (Fig. 2) the dewetting results for a cross pattern with different sizes and in two crystallographic orientations (with branches parallel to $\langle 100\rangle$ and $\langle 110\rangle$ ). In principle, it is important to differentiate between these two directions since in the KMC model only nearest neighbor interactions are concerned. As a result, edges parallel to the $\langle 100\rangle$ direction in KMC (that means the $\langle 110\rangle$ direction in experiments) are more stable in $\mathrm{KMC}$ than those rotated by $45^{\circ} .^{21}$ This influences the density of dewetted islands for crosses oriented with branches in the $\langle 100\rangle$ or in the $\langle 110\rangle$ direction, which results in a difference in the calibration between the two directions of $20 \%$ giving 25 pixels for $1 \mu \mathrm{m}$ in the $\langle 100\rangle$ orientation and 30 pixels for $1 \mu \mathrm{m}$ in the $\langle 110\rangle$ orientation. Once accounted for, the results with the adjusted calibration are very similar for the two orientations we focus here on crosses aligned in the $\langle 110\rangle$ direction.

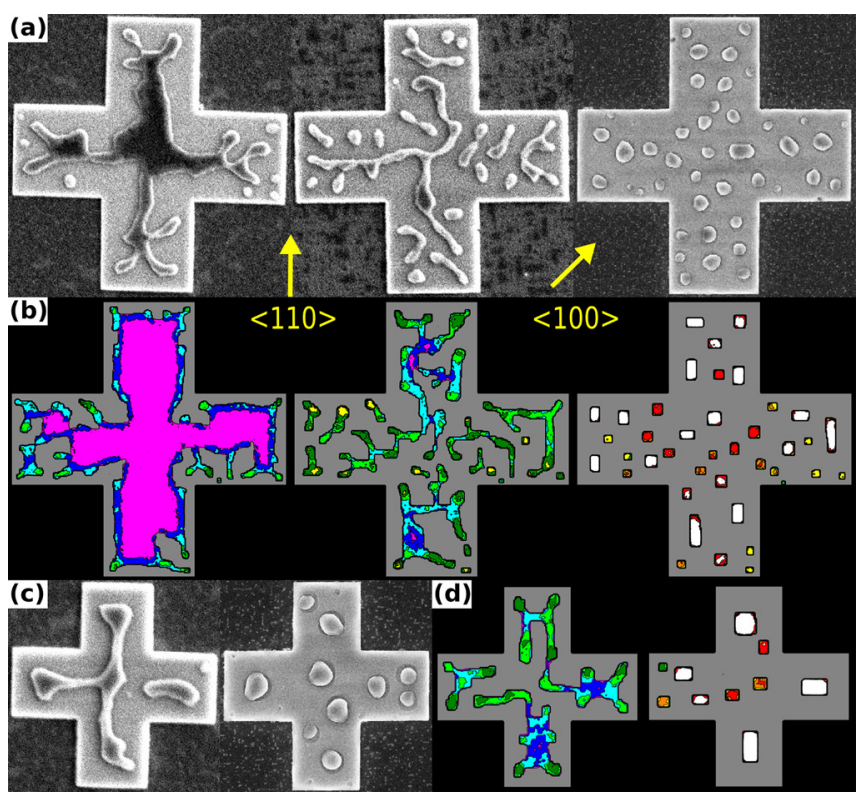

FIG. 2. (a) SEM images of a cross motif with $10 \mu \mathrm{m}$ side length after different stages of dewetting. Experimental conditions: left, A; center, B; and right, C. (b) KMC-simulations with $\mathrm{h}=2, \mathrm{~T}=0.5, \mathrm{E}_{S}=2, \mathrm{~J}=1$, and $300 \times 300 \mathrm{pix}^{2}$, with 300 pix side length. The images are taken after 500 (left), 1000 (center), and 10000 (right) iterations. (c) SEM images of a cross motif with $5 \mu \mathrm{m}$ side length after different stages of dewetting (experimental conditions $\mathrm{A}$ and $\mathrm{C}$ ). (d) KMC-simulations with $\mathrm{h}=2, \mathrm{~T}=0.5, \mathrm{E}_{S}=2$, and $150 \times 150$ pix $^{2}$, with 150 pix side length. The images are taken after 500 and 10000 iterations. 
Figures 2(a) and 2(b) display the experimental and simulated results for a cross with a side length of $10 \mu \mathrm{m}$. In both cases, the fronts retract from the edge of the pattern. Finally, the receding fronts form a wire in the experiment that breaks up into isolated $\mathrm{Si}$ islands. The final state shows a high similarity for the experiment and simulation. Two smaller crosses with a side length of $5 \mu \mathrm{m}$ are imaged in Figs. 2(c) and 2(d).

For this size, the formation of dewetting fingers is almost suppressed, which causes the remaining wires to be oriented in $\langle 110\rangle$ directions. When they break up into isolated islands, the results are again very similar for applications, and the dewetting behavior of wires is of high interest. The inter-island distance and their height can be tuned by the thickness and width of the initial wire pattern so that a single line of well-organized isolated $\mathrm{Si}$ islands may be obtained. Figures 3(a) and 3(b) show the SEM and KMC results for wires with widths of $1,2.5$, and $5 \mu \mathrm{m}$. While the wire with only $1 \mu \mathrm{m}$ width rapidly breaks up into a single line of separated islands, wider wires exhibit an arrangement of several islands next to each other. Figure 3(c) shows the number $N$ of islands per wire length unit, obtained after complete dewetting, versus the width $\ell$ of the wire. Two behaviors are evidenced: below a critical width $\left(\ell_{c} \approx 1 \pm 0.2 \mu \mathrm{m}\right.$ in the experiments) giving birth to a single line of islands, $\mathrm{N} \propto \frac{1}{\sqrt{\ell}}$, whereas above this critical width, $\mathrm{N} \propto \ell$. The $\mathrm{N} \propto \frac{1}{\sqrt{\ell}}$ behavior has already been reported for the dewetting of thin $\mathrm{Ni}$ wires and interpreted as originating from a Rayleigh-like instability. ${ }^{22}$ Beyond this critical width, there is $N \propto \ell / \lambda_{c}$, where $\lambda_{c}$ is the wavelength between islands obtained for $\ell_{c}$. As already mentioned, the $\langle 100\rangle$ direction in KMC simulation fits well the $\langle 110\rangle$ direction in experiments. In KMC, the greatest island density is smaller in $\langle 110\rangle$ than in the $\langle 100\rangle$ direction because the instability of the dewetting rim is very anisotropic and the $\langle 110\rangle$ direction is more stable. ${ }^{23}$

Let us now consider the dewetting mechanisms. The break-up of a wire into 3D islands is sometimes referred to occur due to Rayleigh-Plateau instability. ${ }^{24}$ The Rayleigh instability formally corresponds to the instability that a cylinder of a liquid material with radius $r$ exhibits against periodic perturbations of wavelengths greater than $2 \pi r$. The instability is driven by surface energy minimization and leads to the transformation of the cylinder into a periodic arrangement of droplets. In the case of dewetting wires, three mechanisms of instability are involved altogether. ${ }^{25}$ The first mechanism [Fig. 4(a)] is a Rayleigh-like instability due to mass transfer longitudinally with respect to the wire axis resulting in a periodic height difference. ${ }^{26}$ The second contribution [Fig. $4(b)]$ is a front retraction instability due to the fact that the retraction velocity of a front varies as $E_{s} / h^{3}$ so that the thinner parts of a front recede faster than the thicker ones ( $h$ is the local thickness of the front)..$^{20,23,27}$ Thus, the corresponding mass fluxes are essentially perpendicular to the front. The third mechanism [Fig. 4(c)] is a Mullins-Sekerka type instability due to local perturbations in the position of the triple line and leads to mass fluxes normal to the arc length of the triple line. ${ }^{28}$ These give rise to height variations in the rim due to mass conservation during retraction.

Even if these instabilities may be described independently, they compete with each other and thus are mutually coupled. ${ }^{23,25,29-31}$ Experimental and simulation data show (a)

(b)
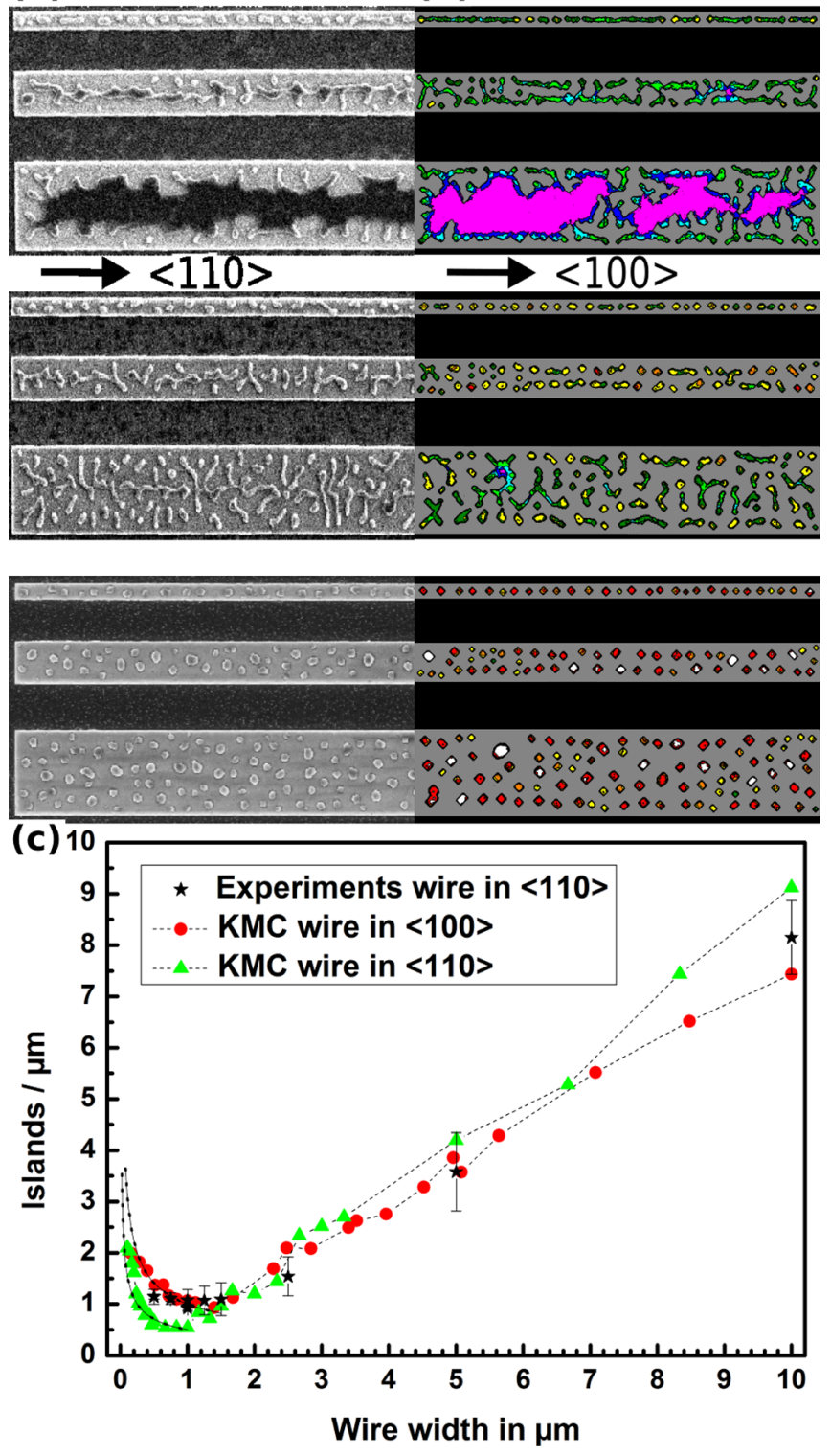

FIG. 3. (a) SEM images of wire motifs with $1,2.5$, and $5 \mu$ m widths after different stages of dewetting. Experimental conditions: top, A; center, B; and bottom, C. (b) KMC-simulations with $\mathrm{h}=2, \mathrm{~T}=0.5, \mathrm{E}_{S}=2$, and $\mathrm{J}=1$, with 25,62 , and 124 pix line widths. The images are taken after 100 (top), 200 (center), and 2000 (bottom) iterations for the small wire, 200, 400 and 2000 iterations for the medium-sized wire and 300, 600 and 2000 iterations for the large wire. (c) Comparison between the experiment and KMC-simulation: Dewetted islands per $\mu \mathrm{m}$ wire length depending on the wire width. The black dotted lines are theoretical curves for $\mathrm{N} \propto \frac{1}{\sqrt{t}}$. (KMC results for the two crystallographic directions have been calibrated with the same ratio as for the crosses).

that the prevailing mechanisms depend on the width $\ell$ of the wire. For this purpose, Fig. 5 shows a few sequences of KMC snapshots that illustrate the evolution over time of dewetting wires. When the wire is too narrow for the formation of a rim, it simply becomes slightly narrower until its height $H$ reaches approximately twice the width $\ell$ of the film [Fig. 5(a)] as expected from equilibrium calculations. Indeed, assuming an infinite and perfectly straight wire, the equilibrium shape is obtained for an aspect ratio $H / \ell=E_{s} /$ $\left(2 \gamma_{100}\right)$. Since at low temperature $\gamma_{100}=J / 2,{ }^{32}$ the equilibrium aspect ratio is $E_{s} / J=2$ in our KMC simulations. Once the equilibrium height is reached, the mass fluxes driving 

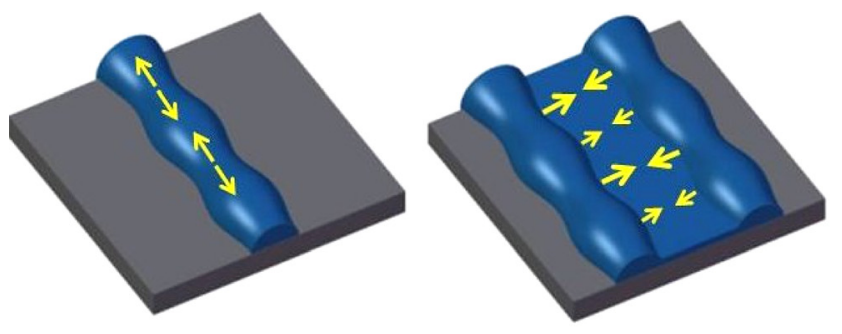

front retraction from the two sides (triple lines) of the wire vanish. The dominant mechanism is the Rayleigh-type instability so that the wire breaks up into $3 \mathrm{D}$ islands separated by a distance proportional to $\sqrt{\ell}$ as already described for a given film thickness. ${ }^{22}$ Slightly larger wires show the formation of a rim and an edge retraction instability that leads to periodic height fluctuations in the dewetting front along the wire [green regions in Fig. 5(b)] without finger formation.



\section{(b)}

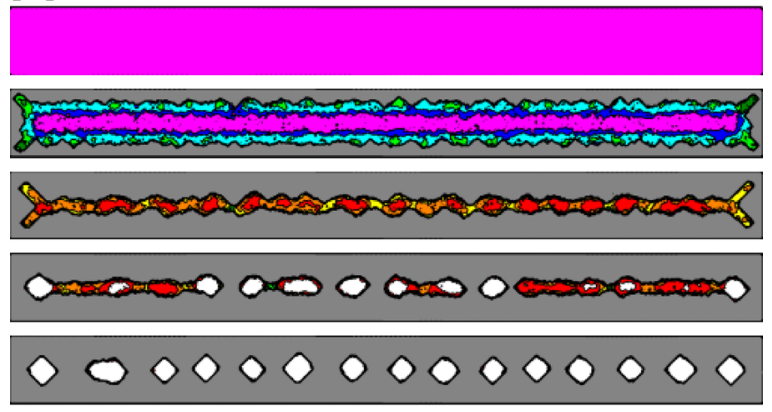

\section{(c)}
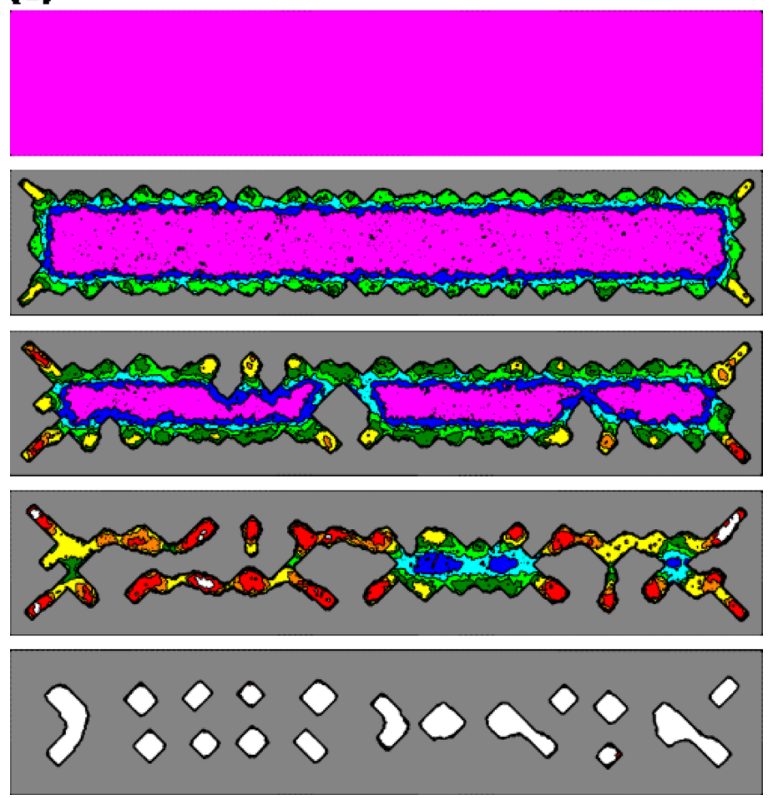

FIG. 5. KMC simulations with $\mathrm{h}=3, \mathrm{~T}=0.5$, and $\mathrm{E}_{S}=2$ representing 3 thickness-dependent scenarios for the dewetting of a wire. (a) Initial wire width, 10 pixels. The images are taken after $0,50,100$, and 500 iterations. (b) Initial wire width, 40 pixels. The images are taken after 0, 200, 700, 2000, and 5000 iterations. (c) Initial wire width, 80 pixels. The images are taken after $0,1000,2000,3000$, and 10000 iterations.

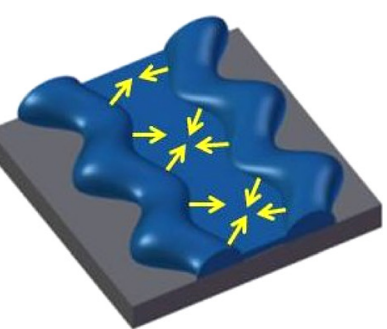

FIG. 4. Main mass transfer mechanisms (yellow arrows): (a) Rayleigh type instability of a wire, (b) retraction instability in presence of a rim, and (c) Mullins-Sekerka type instability.

Theoretical studies have predicted that the wavelength of the instability of the rim edge should grow slowly in time. ${ }^{23,30,31}$ When the wire height reaches twice its width, the effect of the front retraction once again cancels out. However, this time there is already an apparent periodicity in the wire that determines the inter-island distance upon breaking-up. This emphasizes the strong influence of the edge retraction instability (the lower regions retract faster than the higher ones), whereas the breaking-up itself occurs due to Mullins-Sekerka and Rayleigh instabilities.

In the case of wide wires [Fig. 5(c)], the instability develops beyond the initial stages analyzed in Refs. 23, 25, and 29-31, and Si fingers start to appear. These fingers themselves bead into 3D islands via the Rayleigh-Plateau instability. Since the beading is essentially a periodic phenomenon, the number of beads is roughly proportional to the length of the fingers and thus to the initial wire width. Hence, for wide wires, the formation of islands is controlled by finger beading and $N \propto \ell$.

Summing up, (1) a simple KMC code reproduces the dewetting of various patterns and exhibits some predictive power; (2) The prevailing mechanism of instability depends on the pattern width: Narrow wires break up into a periodic line of $3 \mathrm{D}$ islands via a Rayleigh-type instability with $\mathrm{N} \propto \frac{1}{\sqrt{\ell}}$. Larger wires essentially destabilize by retraction instability. For very large wires, the dominant contribution is beading, leading to $N \propto \ell$.

The authors thank F. Bedu and I. Ozerov for sample preparation at PLANETE (C'Nano PACA) and J.-C. Barbé (LETI) for providing us SOI samples. We acknowledge ANR-13-BS04-0004-02 Grant LOTUS for financial support.

${ }^{1}$ C. Thompson, Annu. Rev. Matter. Res. 30, 159 (2000).

${ }^{2}$ C. Thompson, Annu. Rev. Matter. Res. 42, 399 (2012).

${ }^{3}$ F. Cheynis, F. Leroy, and P. Müller, C. R. Phys. 14, 578 (2013).

${ }^{4}$ F. Leroy, L. Borowik, F. Cheynis, Y. Almodori, S. Curiotto, M.

Trautmann, J. Barbe, and P. Müller, Surf. Sci. Rep. 71, 391 (2016).

${ }^{5}$ Y. Ishikawa, Y. Imai, H. Ikeda, and M. Tabe, Appl. Phys. Lett. 83, 3162 (2003).

${ }^{6}$ J. Ye and C. Thompson, Phys. Rev. B. 82, 193408 (2010).

${ }^{7}$ M. Aoussa, I. Berbezier, L. Favre, A. Ronda, M. Bolani, R. Sordan, A. Delobbe, and P. Sudraud, Appl. Phys. Lett. 101, 013117 (2012).

${ }^{8}$ A. Benkouider, A. Ronda, T. David, L. Favre, M. Abbarchi, M. Naffouti, J. Osmond, A. Delobbe, P. Sudraud, and I. Berbezier, Nanotechnology 26, 505602 (2015).

${ }^{9}$ J. Ye, Sci. Rep. 5, 9823 (2015).

${ }^{10}$ M. Abbarchi, M. Naffouti, B. Vial, A. Benkouider, L. Lermusiaux, L. Favre, A. Ronda, S. Bidault, I. Berbezier, and N. Bonod, ACS Nano 8, 11181 (2014).

${ }^{11}$ D. Kim, A. L. Giermann, and C. V. Thompson, Appl. Phys. Lett. 95, 251903 (2009).

${ }^{12}$ J. Ye and C. Thompson, Adv. Mater. 23, 1476 (2011).

${ }^{13}$ M. Naffouti, T. David, A. Benkouider, L. Favre, A. Delobbe, A. Ronda, I. Berbezier, and M. Abbarchi, Small 12, 6115 (2016). 
${ }^{14}$ M. Krupinski, M. Przanowski, A. Zarzycki, Y. Zabila, and M. Marszalek, Nanotechnology 26, 425301 (2015).

${ }^{15}$ O. Pierre-Louis, A. Chame, and Y. Saito, Phys. Rev. Lett. 103, 195501 (2009).

${ }^{16}$ E. Bussmann, F. Cheynis, F. Leroy, P. Müller, and O. Pierre-Louis, New J. Phys. 13, 043017 (2011).

${ }^{17}$ E. Bussmann, F. Cheynis, F. Leroy, and P. Müller, IOP Conf. Ser.: Mater. Sci. Eng. 12, 012016 (2010).

${ }^{18}$ M. Trautmann, F. Cheynis, F. Leroy, S. Curiotto, and P. Müller, Appl. Phys. Lett. 110, 161601 (2017).

${ }^{19}$ F. Cheynis, E. Bussmann, F. Leroy, T. Passanante, and P. Müller, Phys. Rev. B. 84, 245439 (2011).

${ }^{20}$ F. Leroy, F. Cheynis, T. Passanante, and P. Müller, Phys. Rev. B. 88, 035306 (2013).

${ }^{21}$ F. Leroy, F. Cheynis, T. Passanante, and P. Müller, Phys. Rev. B 85, 195414 (2012).
${ }^{22}$ G. H. Kim and C. V. Thompson, Acta Mater. 84, 190 (2015).

${ }^{23}$ A. Chame and O. Pierre-Louis, C. R. Phys. 14, 553 (2013).

${ }^{24}$ M. S. McCallum, P. W. Voorhees, M. J. Miksis, S. H. Davis, and H. Wong, J. Appl. Phys. 79, 7604 (1996).

${ }^{25}$ R. V. Zucker, "Capillary-driven shape evolution in solid-state micro- and nano-scale systems," Ph.D. thesis (Massachusetts Institute of Technology, 2009).

${ }^{26}$ L. Rayleigh, Proc. London Math. Soc. s1-10, 4 (1878).

${ }^{27}$ E. Jiran and C. Thompson, J. Electron. Mater. 19, 1153 (1990).

${ }^{28}$ W. W. Mullins and R. F. Sekerka, J. Appl. Phys. 35, 444 (1964).

${ }^{29}$ W. Kan and H. Wong, J. Appl. Phys. 97, 043515 (2005).

${ }^{30}$ M. Dufay and O. Pierre-Louis, Phys. Rev. Lett. 106, 105506 (2011).

${ }^{31}$ M. Dziwnik, M. Korzec, A. Münch, and B. Wagner, Multiscale Model. Simul. 12, 755 (2014).

${ }^{32}$ Y. Saito, M. Ignacio, and O. Pierre-Louis, C. R. Phys. 14, 619 (2013). 